\title{
Levinas e a reconstrução da subjetividade ética aproximações com o campo da educação
}

\author{
JOSÉ VALDINEI ALBUQUERQUE DE MIRANDA \\ Universidade Federal do Pará, Cametá, PA, Brasil
}

RESUMO

Este artigo tem por objetivo discutir o conceito de subjetividade em sua relação com a alteridade em educação, com base no pensamento filosófico de Emanuel Levinas. Inicialmente, apresenta a discussão da subjetividade na filosofia moderna e sua forma de concebê-la como ideal de sujeito livre e soberano. Em seguida, desenvolve uma análise crítica que problematiza a pretensa soberania do sujeito e reconstrói uma nova subjetividade ética, situada na condição de refém, capaz de acolher a irredutível alteridade do Outro enquanto ideia do infinito. No contexto de reconstrução da subjetividade, o estudo estabelece aproximações com o campo da educação, destacando a experiência educativa como um acontecimento ético por excelência.

\section{PALAVRAS-CHAVE}

subjetividade; alteridade; ética; educação. 


\title{
LEVINAS AND THE RECONSTRUCTION OF THE ETHICAL SUBJECTIVITY: APPROACHES TO THE FIELD OF EDUCATION
}

\begin{abstract}
This article aims to discuss the concept of subjectivity in its relation to otherness in education, based on the philosophical thought of Emanuel Levinas. First, it presents the discussion of subjectivity in modern philosophy, and his way of conceiving it as an ideal of free and sovereign subject. Then it develops a critical analysis that problematizes the alleged sovereignty of the subject and reconstructs a new ethical subjectivity, located in the condition of hostage, capable of accommodating the irreducible alterity of the other as an idea of infinity. In the context of the reconstruction of subjectivity, the study establishes approaches to the field of education, emphasizing the educational experience as an ethical event par excellence.
\end{abstract}

KEYWORDS

subjectivity; otherness; ethics; education.

\section{LEVINAS Y LA RECONSTRUCCIÓN DE LA SUBJETIVIDAD ÉTICA: ACERCAMIENTOS CON EL CAMPO DE LA EDUCACIÓN}

\section{RESUMEN}

Este trabajo pretende analizar el concepto de subjetividad en su relación con la alteridad en la educación, desde el pensamiento filosófico de Emmanuel Levinas. Inicialmente se presenta una discusión de la subjetividad en la filosofía moderna, y su forma de concebirla como un ideal de sujeto libre y soberano. A continuación, se desarrolla un análisis crítico que cuestiona la supuesta soberanía del sujeto y la reconstrucción de una nueva subjetividad ética, situada en la condición de rehén, con capacidad para acoger la irreductible alteridad del otro, en tanto que la idea del infinito. En el contexto de la reconstrucción de la subjetividad, el estudio ofrece aproximaciones a la esfera de la educación destacando la experiencia educativa como un acontecimiento ético por excelencia.

PALABRAS CLAVE

subjetividad; alteridad; ética; educación. 


\section{INTRODUÇÃO}

Este trabalho visa discutir a questão da subjetividade e sua relação com a alteridade na educação com base no pensamento de Emanuel Levinas. A opção pelo pensamento de Levinas está relacionada ao fato de esse filósofo, ao longo de sua trajetória intelectual, especialmente em suas obras Totalidade e infinito (1961) e De otro modo que ser, o más allá de la esencia (1974), realizar uma profunda reconstrução da subjetividade pela perspectiva ética da relação com o Outro, além de fazer de sua filosofia uma refinada discussão sobre a complexa questão da alteridade, expondo os limites de uma "racionalidade egológica" que funda no Mesmo o processo de representação e objetivação do Outro, adequando-o a um sistema de totalidade.

Inicialmente, o artigo apresenta a discussão da subjetividade no contexto do pensamento filosófico moderno e sua forma de concebê-la com base no ideal de construção do sujeito livre e soberano. No contexto de crise da subjetividade moderna, o estudo segue as pistas deixadas por Levinas na sua crítica à soberania do sujeito, apontando sua destituição. Nesse trabalho de crítica e reconstrução, o filósofo apresenta os caminhos da sensibilidade como fruição, contato e vulnerabilidade - o que possibilita pensar uma nova subjetividade ética, situada na condição de refém e capaz de acolher a irredutível alteridade do Outro enquanto ideia do infinito. Nesse processo de reconstrução, a subjetividade é discutida não por meio da centralidade do sujeito autônomo, mas a partir da alteridade do Outro - fato que permite a descrição da subjetividade nos termos de acolhimento e responsabilidade pelo Outro.

Situados no contexto da reconstrução da subjetividade ética operada por Levinas e sua relação com a alteridade no campo da educação, são apresentados alguns questionamentos que servem como balizadores das discussões: Que significa pensar a relação com o Outro na educação valendo-se da perspectiva reconstrução da subjetividade ética? Como abordar a educação por uma perspectiva ética da alteridade? Como pensar o Outro na educação para além de sua objetivação e representação? Que desafios e implicações o pensamento ético da alteridade apresenta para a educação? Como educar para a alteridade?

Portanto, neste trabalho as discussões referentes à reconstrução da subjetividade e sua relação com a alteridade são abordadas como questões a serem pensadas nas mediações entre filosofia e educação, mais especificamente entre o pensamento ético da alteridade desenvolvido por Levinas e suas contribuições para um novo pensar a relação $\mathrm{Eu}-\mathrm{Outro}$ na educação.

\section{SUBJETIVIDADE E A CONSTRUÇÃO DO SUJEITO MODERNO}

$\mathrm{Na}$ modernidade, a subjetividade é pensada com base na centralidade do "Eu" e encontra na vontade racional o fundamento de sustentação para a formação de um sujeito livre e soberano. Ao instituir o "Eu" como a unidade integradora do sentido e da representação, a filosofia moderna - que tem nas figuras de Descartes 
e Kant seus principais expoentes - ergue a subjetividade sobre as bases de uma vontade racional. No contexto dessa filosofia, "o homem, enquanto sujeito, é o princípio ordenador do qual emana o sentido e as representações da realidade" (Hermann, 2006, p. 11).

Com o advento da modernidade, encontramos a passagem de uma discussão que assumia o ser (ontologia) como centralidade dos problemas filosóficos característica da filosofia medieval - para uma ênfase na problematização do conhecimento (epistemologia). Passagem esta que marca o início do pensamento filosófico da modernidade. Nesse momento, René Descartes (1596-1650) é considerado o grande pensador que inaugura uma tradição filosófica, pois encontra no princípio da subjetividade, no "eu penso", o autêntico "ponto arquimediano"1 sobre o qual será erguido o conhecimento e garantida a certeza da verdade. Partindo da dúvida metódica como caminho filosófico, Descartes (1989, p. 43-45) chega ao "penso, logo existo" como fundamento de sua filosofia, expresso da seguinte maneira:

$\mathrm{E}$, finalmente, considerando que todos os pensamentos que temos quando acordamos também nos podem ocorrer quando dormimos, sem que nenhum seja tão verdadeiro, resolvi fingir que todas as coisas que haviam entrado em meu espírito não eram mais verdadeiras que as ilusões de meus sonhos. Mas logo depois entendi que, enquanto queria pensar assim, que tudo era falso, era necessariamente preciso que eu, que o pensava, fosse alguma coisa. E notando que esta verdade - penso, logo existo - era tão firme e tão certa que todas as mais extravagantes suposições dos céticos não eram capazes de abalar, julguei que podia admiti-la sem escrúpulo como o primeiro princípio da filosofia que buscava.

No pensamento cartesiano, a questão da subjetividade aparece ligada à noção de cogito, concebido como certeza indubitável e capaz de servir de fundamento racional a toda explicação sobre o conhecimento. Ao afirmar o "eu penso" como "ponto arquimediano" fundador de toda certeza do conhecimento, Descartes promove uma verdadeira revolução na tradição do pensamento filosófico ocidental e institui o princípio da subjetividade como um porto seguro sobre o qual deve ser erguida toda e qualquer certeza filosófica.

Essa "virada epistemológica" iniciada com Descartes no século XVII ganhará na filosofia de Immanuel Kant (1724-804), no século XVIII, a sua expressão mais acabada. Ao se perguntar pelas condições e possibilidades do conhecimento, Kant

1 Descartes (2004), em suas “meditações”, busca incessantemente encontrar um "ponto arquimediano" capaz de fundar toda certeza do conhecimento. Nesse processo de busca filosófica, faz referência a Arquimedes, que, para tirar o globo terrestre de seu lugar e transportá-lo para outra parte, não pedia nada mais que um ponto que fosse fixo e seguro. Do mesmo modo que Arquimedes, Descartes pretendia erguer seu pensamento sobre as bases de uma certeza fundante e indubitável. A síntese dessa certeza pode ser apresentada por sua máxima: "penso, logo existo". 
(1980) encontra no sujeito racional (e não nos objetos) a garantia de todo conhecimento verdadeiro. Tomando por base as contribuições deixadas pelo pensamento cartesiano, Kant realiza uma profunda e sofisticada discussão filosófica, a qual assume a tarefa de explicar os fundamentos do pensamento e da ação do homem. Kuiava (2003) destaca que, nessa busca pela fundamentação do conhecimento e do agir humano, Kant encontra na estrutura da subjetividade do "Eu transcendental" a base capaz de sustentar a objetivação e a universalização do conhecimento teórico e de determinar o princípio de validação das normas do agir moral.

Em Kant, a questão da subjetividade ${ }^{2}$ pode ser situada em meio à discussão do sujeito sensivel ou empirico e do sujeito inteligivel ou transcendental; como sujeito sensível, o Eu recebe de modo determinante as influências externas do mundo. Nessa condição, Kant (1980) destaca que o sujeito faz parte da natureza e seus atos estão condicionados ao determinismo universal, diferenciando-se, assim, do caráter inteligível, que, nesse aspecto, escapa do mundo dos fenômenos e passa a fazer uso de sua liberdade. Enquanto consciência empírica, o sujeito ainda é passivamente afetado pelas representações do mundo que não provêm de si mesmo, ou seja, o sujeito empírico é governado por leis que se apresentam como externas ao seu domínio. Sua existência ainda não está no plano da liberdade. Contrariamente ao sujeito empírico, o sujeito transcendental é capaz de realizar - por sua autonomia o pleno exercício da liberdade.

Desse modo, em Kant, liberdade e autonomia são categorias filosóficas que estão intimamente entrelaçadas, uma vez que o sujeito só alcançará sua verdadeira liberdade passando de um estado de heteronomia a um estado de autonomia em seu agir moral. A esse respeito, Kuiava (2003) considera que em Kant o processo de humanização ocorre quando o Eu autônomo passa a escolher livremente a ação que deve seguir conforme sua vontade. Nessa perspectiva, a ética é vista como o lugar privilegiado no qual acontece a emancipação do ser humano como ser que se edifica a si mesmo, à medida que se autodetermina.

Com base na fundamentação da subjetividade como unidade integradora do sentido e da representação, podemos entender o sujeito moderno como o grande legislador do mundo, isto é, o sujeito que autonomamente é capaz de criar e seguir livremente suas próprias leis. Um sujeito capaz de estabelecer critérios racionais de organização social aos diferentes modos de vida com vistas a garantir o melhor convívio entre as diferentes culturas e sociedades, além de instituir racionalmente e seguir livremente as normas que orientam seu agir moral. Essa foi a grande aposta do projeto filosófico iluminista na modernidade.

2 Sem a pretensão de discutir detalhadamente a constituição da subjetividade em Kant, mas com a intenção de situar o contexto em que o princípio da subjetividade é por ele assumido como fundamento da sua filosofia, teço apenas algumas considerações sobre o pensamento kantiano, especificamente no que concerne ao modo de conceber o tema da subjetividade. Para um estudo mais aprofundado sobre a questão da subjetividade em Kant, destaca-se a pesquisa de Kuiava (2003). 
Com isso, a filosofia moderna encontra na subjetividade seu porto seguro. Isso porque a subjetividade, enquanto um princípio filosófico que funda o "Eu" como centralidade e justificação de uma vontade racional, serve como pressuposto sobre o qual se ergue toda a estrutura arquitetônica dos ideais da modernidade. Em outros termos, podemos dizer que a subjetividade moderna, fundamentada racionalmente na soberania do Eu, apresenta como télos de sua realização a construção de um sujeito livre e autônomo. Isso demarca, no contexto da modernidade, o surgimento da ideia de sujeito enquanto unidade de sentido e de representação, capaz de integrar em si uma multiplicidade de significações do mundo. Portanto, na modernidade, o princípio da subjetividade assume a centralidade nas discussões filosóficas, uma vez que é concebido como fundamento do conhecimento e da própria filosofia.

Em sua análise sobre a questão da subjetividade na modernidade, Hermann (2006) destaca a complexidade presente no tema do sujeito e o entrecruzamento de um conjunto de tradições filosóficas que, ao formularem os entendimentos sobre o humano, a ética, a ciência e a política, consequentemente definiram também as bases de sustentação do projeto pedagógico moderno. "Essas tradições podem expressar-se pelo princípio filosófico da subjetividade, que determina a soberania do sujeito racional, fazendo valer o seu próprio discernimento" (idem, p. 11).

O ideal de sujeito soberano edificado pelos princípios da liberdade e da autonomia presente em Descartes e Kant servem de base na orientação da formação do homem moderno. Esses princípios de formação do homem são traduzidos para o contexto da educação (enquanto instituição escolar) e passam a orientar a formação do sujeito (aluno, aprendiz, educando) tendo em vista o exercício de seu livre pensar e a autonomia de seu agir moral. A pretensão de universalização do ensino por meio da institucionalização da educação escolar é uma reivindicação histórica que nasce no contexto da modernidade e que encontra no princípio da liberdade e da autonomia do sujeito os pilares de sua sustentação como correta orientação na formação moral do homem.

A formação do sujeito moderno perpassa as dimensões político-social, epistemológica e moral - conforme aponta Chaui (2000). Nessas dimensões, o sujeito racional deve ser capaz de realizar as diferentes "formas de consciência": ${ }^{3}$ a consciência politica e social (assentada no ideal do sujeito consciente de seus direitos e deveres, emancipado em suas ações e consciente de seu papel no processo de transformação histórica da sociedade); a consciência epistemológica (caracterizada pelo ideal do sujeito capaz de sair de um estado de heteronomia e alcançar um estado de autonomia do seu pensar, ou seja, capaz de construir o seu próprio conhecimento e pensar por si mesmo); e a consciência moral (fundada no ideal de um sujeito capaz de instituir e seguir livremente sua própria lei, saindo de um estágio de menoridade moral e

3 Similar às análises de Marilena Chaui a respeito das dimensões que constituem o ideal de sujeito moderno, Ghiraldelli Júnior (2000) apresenta quatro "formas de consciência" que constituem a subjetividade: o Eu (consciência psíquica/self); a pessoa (consciência moral); o cidadão (consciência política); e o sujeito epistêmico (consciência intelectual). 
alcançando sua maioridade). Lembremos aqui o imperativo categórico Kantiano que postula, na plena autonomia do sujeito, o princípio mais elevado da lei moral.

Nessas formas de consciência, a filosofia moderna buscou garantir a formação do ideal do sujeito soberano. Entretanto, como destaca Hermann (2006, p. 9),

apesar do brilho do projeto moderno em sua crença na força do sujeito racional [...] o contradiscurso do iluminismo, especialmente o movimento Romântico, inicia uma crítica à ideia de sujeito soberano, que supostamente dominaria a si mesmo e ao mundo.

Com as críticas dirigidas à subjetividade moderna, presentes já no Romantismo do século XVIII e ganhando força nos séculos XIX e XX com alguns filósofos "mestres da suspeita" - com Nietzsche decretando a morte de Deus; Freud, com a descoberta do inconsciente; Heidegger e sua crítica radical à "metafísica da subjetividade" moderna; Foucault, com a afirmação da morte do sujeito moderno -, entram em questionamento os próprios fundamentos ou as bases de sustentação da filosofia da subjetividade moderna erguida na centralidade do Eu.

Essas críticas colocam em suspeita a possibilidade de realização do projeto filosófico pensado na modernidade. Nesse momento, “a reflexão filosófica não cessa de criticar o sujeito soberano, expondo as mazelas, os limites e as aporias da filosofia da subjetividade, que objetualiza as relações, impedindo a intersubjetividade e o reconhecimento do outro" (idem, p. 10). Em meio a esse cenário de suspeita e de crítica, a autossegurança de um sujeito soberano passa a ser questionada num movimento permanente, que procura voltar o olhar ao espelho de sua própria face em busca de novas formas de compreensão e justificação para os acontecimentos históricos e para os problemas filosóficos que constituem a sua tradição.

No plano antropológico, a crítica dos fundamentos da filosofia moderna significou o questionamento dos diferentes modos de representação e domínio do Outro e das formas etnocêntricas de concebê-lo como um externo à sua cultura; no plano filosófico, significou um questionamento radical dos fundamentos que sustentam o pensamento moderno, apontando um duplo movimento de "desconstrução" e "reconstrução" dos princípios fundados na vontade racional e na centralidade do Eu. Desconstruir os princípios da filosofia moderna não significa, para os filósofos reconstrucionistas, que o ideal de emancipação do sujeito possa ser descartado, uma vez que, como afirma Habermas (2002), o projeto filosófico da modernidade ainda é um "projeto inacabado", podendo a própria ideia de sujeito ser redimensionada pela incorporação de novos elementos filosóficos.

Historicamente, a liberdade e a autonomia, como princípios clássicos da filosofia moderna, servem de orientação para a concepção de formação moral do homem, a ser implementada pela educação. A partir de então, educar passa a significar formar o homem para o exercício de sua plena liberdade e para a autonomia moral no seu agir na sociedade. Liberdade e autonomia, mesmo com nuances diferentes, são princípios que secularmente servem de orientação às diferentes perspectivas teóricas e propostas pedagógicas no campo educacional. 
Portanto, ao entrarem em crise os fundamentos da filosofia moderna, os próprios princípios que sustentam a educação institucionalizada também se desestabilizam. Isso não significa dizer que a relação entre filosofia e educação seja construída por automatismos, nem que os fundamentos filosóficos governem por completo a educação, mas sim destacar a estreita relação existente entre filosofia e educação, que faz com que a crise dos fundamentos da filosofia desestabilize os princípios de justificação da educação, questionando seus pressupostos de sustentação como um todo. Em virtude dessa estreita relação, a crise da razão e da subjetividade moderna, no campo da filosofia, também provoca uma tensão nos pressupostos que orientam a formação do sujeito, levando, com isso, a educação a buscar novas formas de justificação e de ressignificação de seu fazer pedagógico.

\section{LEVINAS E A RECONSTRUÇÃO DA SUBJETIVIDADE}

No cenário da filosofia contemporânea, Levinas (1906-1995) ficou conhecido como o pensador da alteridade, o filósofo que ousou dar visibilidade à questão do Outro e colocar a alteridade no centro da cena filosófica. De fato, em Levinas a alteridade ganha relevância e assume um papel central na construção de uma ética pensada como filosofia primeira. A alteridade é o elemento novo que promove uma ruptura epistemológica com o pensamento da tradição filosófica e marca a originalidade de Levinas como filósofo que pensa o até então impensado. Entretanto, como ressalta Susin (1992), em Levinas não encontramos uma descrição fenomenológica acerca do Outro; por isso, não podemos falar nem sobre a alteridade nem com base na alteridade. $\mathrm{O}$ que podemos falar é como a subjetividade se reconstrói ao passar pelo desafio e prova da relação com o absolutamente Outro.

A filosofia de Levinas pode ser lida como uma profunda descrição fenomenológica da subjetividade, que inscreve na estrutura "um-para-o-outro" o sentido eminentemente ético do humano. Nessa perspectiva, o discurso de Levinas não seria um discurso sobre a alteridade, mas "um discurso da subjetividade que circunda ou que violenta ou que responde ou que serve a alteridade" (idem, p. 367). Com base nesse entendimento, não podemos abordar a questão da alteridade em Levinas sem antes compreender como ele realiza a destituição da soberania do sujeito e reconstrói uma nova subjetividade ética descrita na forma do acolhimento e responsabilidade pelo Outro.

No contexto de crise da subjetividade moderna, a filosofia de Levinas apresenta-se como uma das alternativas que procuram pensar a subjetividade pela perspectiva ética da relação com o Outro. Para esse filósofo, a proposta de construção de um sentido ético para o humano implica reconstruir a subjetividade não mais a partir da centralidade do Eu, mas pela estrutura um-para-o-outro, na qual a subjetividade é descrita nos termos do acolhimento e da responsabilidade, até a substituição um-pelo-outro, ou seja, uma subjetividade ética que já na sua constituição é afetada pela alteridade. 
Tomando a estrutura um-para-o-outro, Levinas busca pensar a subjetividade para além dos domínios do ser e da centralidade do sujeito soberano. A subjetividade não é descrita no contexto da ontologia, pois o ser é identificado como egoísmo, interesse e permanência em si, conatus essendi, ${ }^{4}$ incapaz de realizar o movimento de transcendência ao Outro, como também não é erigida pelos princípios da liberdade e da autonomia do sujeito racional. $\mathrm{O}$ ideal de sujeito soberano não serve de referência última para a construção da subjetividade, pelo contrário, Levinas considera que esse modo de abordar a subjetividade levou à construção de um tipo de pensamento que se instituiu historicamente como um pensar do Mesmo sobre o Outro. Esse diagnóstico sobre a tradição filosófica ocidental é descrito por esse filósofo como o império da "filosofia do Mesmo", ou seja, um tipo de pensamento que tematiza e representa o Outro por meio da categoria da totalidade e por isso permanece alérgico à sua irredutível alteridade.

Levinas procura reconstruir a subjetividade não mais na perspectiva do sujeito soberano, com um domínio total de si, mas na perspectiva de edificação de uma subjetividade acolhedora, exposta e vulnerável ao Outro, ou seja, uma subjetividade constituída, desde o seu nascimento anárquico, pela alteridade do Outro. A alteridade é um elemento constitutivo da subjetividade ética. A abordagem da alteridade em Levinas situa-se em um registro que pretende mostrar que a presença irredutível do Outro inquieta constantemente a autonomia do Eu, chamando-o à responsabilidade ética. A alteridade do Outro anima e mantém viva a intriga na relação ética, pois provoca uma abertura na consciência do "Eu" fazendo, com isso, vibrar na egologia do ser o sopro ético que anuncia o nascimento de uma nova relação com a alteridade.

Desse modo, a alteridade do Outro constitui a subjetividade ética em Levinas. Uma subjetividade descrita como acolhimento, na forma de hospitalidade ao estrangeiro que nos vem ao encontro e resposta no sentido de que assume a insubstituível responsabilidade pelo Outro até a substituição. Com isso, ao reconstruir a subjetividade, Levinas cria as possibilidades de edificação de um novo humanismo - um humanismo do outro homem. Um homem que, antes de ser livre e autônomo, é responsável e capaz de acolher o Outro na sua absoluta alteridade. É nesse cenário que o pensamento filosófico de Levinas se apresenta como uma racionalidade radicalmente ética, capaz de reconstruir a subjetividade desde a estrutura um-para-o-outro na relação com o próximo.

Nessa reconstrução, a espontaneidade da liberdade é posta em questão e chamada a justificar-se. A responsabilidade é pensada não como uma predisposição existencial do sujeito já constituído, que decide livremente assumir sua responsabilidade, mas como o elemento que define a unicidade do sujeito, ou seja,

4 A esse respeito, destaca-se a pesquisa de Marcelo Pelizzoli (2002) sobre a reconstrução da subjetividade em Levinas, na qual o autor discute a questão do conatus essendi como um conceito-chave no sentido de perseverança no ser para si, no interior de uma ego-ontologia situada no contraponto da abertura à alteridade e seu primado. 
a responsabilidade é o elemento que antecede a liberdade do humano e constitui a própria subjetividade. Essa inversão nos termos da relação ética aponta para a construção de uma nova subjetividade, descrita como acolhimento e resposta ao Outro. Eis a reconstrução da subjetividade ética operada por Levinas, como questão filosófica central de seu pensamento.

Se na modernidade a autonomia do sujeito é concebida como princípio moral mais elevado, na reconstrução da subjetividade ética pensada por Levinas o sujeito autônomo passa por um processo de destituição de sua soberania. Por meio da descrição fenomenológica da subjetividade, a soberania do sujeito é tensionada e colocada em questão: o Eu é deposto de seu reinado absoluto. A crítica e destituição do sujeito soberano permitem a reconstrução de uma nova subjetividade, descrita com base em um sujeito sujeitado que se constitui como "refém do Outro". Portanto, ao mesmo tempo em que ocorre a destituição do sujeito soberano, realiza-se também a reconstrução de uma nova subjetividade ética, erguida com base na estrutura um-para-o-outro e descrita em termos de acolhimento e responsabilidade pelo Outro.

No contexto da destituição do sujeito soberano, incapaz de ouvir algo além de sua própria voz e incapaz de encontrar no Outro algo mais do que si mesmo, Levinas descreve a subjetividade como lugar de exílio e exposição e pensa a relação ética com base na primazia do Outro sobre o Mesmo. Portanto, a destituição da soberania do Eu é um movimento fenomenológico que cria as condições de possibilidade para que uma nova subjetividade ética possa ser reconstruída por meio da estrutura um-para-o-outro. "Somente um eu destituído da sua soberania poderá ser realmente ético” (Kuiava, 2003, p. 147).

Levinas realiza a sua análise fenomenológica valendo-se de um duplo movimento caracterizado pela destituição da centralidade e soberania do Eu e pela abertura e reconstrução de uma nova subjetividade constituída pelo Outro. Nesse processo, a "racionalidade egológica" é colocada em questão, e o resultado dessa crítica possibilita o surgimento de uma "racionalidade ética", ${ }^{5}$ significando, com isso, que a racionalidade passa a ser entendida pela perspectiva da ética como flosofia primeira. Em busca do sentido do humano, o filósofo elabora uma verdadeira reconstrução da subjetividade e conjuntamente recria uma nova relação ética com a alteridade, inscrita na relação face a face, em que o Outro não é simplesmente representado e integrado à estrutura do $\mathrm{Eu}$, ao contrário, o Outro é transbordamento, pura inadequação às categorias do Eu, uma absoluta alteridade na qual se expressa a ideia de infinito. Essa compreensão mantém a exterioridade do Outro na relação e permite descrever a subjetividade nos termos de acolhimento e hospitalidade ao

5 "Racionalidade ética" é uma expressão utilizada por comentadores de Levinas para situar a mudança de perspectiva da relação ética. A racionalidade ética situa o Outro na posição insubstituível da alteridade, levando, com isso, a potência da razão aos seus próprios limites. Uma racionalidade ética coloca em questão a própria liberdade do sujeito, uma vez que pensa a responsabilidade pelo Outro como o elemento que constitui a própria subjetividade enquanto racionalidade situada na órbita da vontade de justiça (Souza, 2004). 
Outro. Portanto, em Levinas, a epifania do Outro expressa uma interpelação ética que desfaz a imagem plástica e a representação que dele se tem, ou seja, o encontro com o Outro é um convite à hospitalidade.

\section{A EDUCAÇÃO COMO ACONTECIMENTO ÉTICO}

Com base nas discussões realizadas nos tópicos anteriores referentes à questão da subjetividade na modernidade e a reconstrução da subjetividade em Levinas, procuro, neste momento, iniciar um exercício de pensar a educação pela perspectiva ética da alteridade. Tendo em vista esse objetivo, apresento inicialmente alguns questionamentos que visam abrir caminho e estreitar o vínculo da relação entre ética e educação: O que significa pensar a educação pela perspectiva ética da alteridade? Em que sentido a relação ética com o Outro pode ser vinculada à experiência educativa?

Esses questionamentos situam a problemática central da relação entre subjetividade e alteridade no cruzamento entre ética e educação e abrem caminho para a discussão da experiência educativa para além do contexto estritamente epistemológico da ciência moderna, caracterizado pela relação sujeito-objeto no processo de construção do conhecimento. Essas perguntas deslocam a discussão da educação de um cenário governado por uma racionalidade técnica e instrumental para um contexto eminentemente ético no qual a educação é compreendida como acontecimento ético e a experiência educativa é abordada na sua relação com o Outro. Uma perspectiva ética da alteridade nos permite problematizar os modos de representação e objetivação do Outro, bem como discutir suas implicações para o campo da educação.

Pensar a educação como acontecimento ético implica fazer da experiência educativa um lugar de encontro com o Outro; significa, de modo contrário à relação que visa à objetivação do Outro na educação, estar disposto a lançar-se a novos horizontes desconhecidos, expondo-se, com isso, ao inesperado, ao imprevisível, ao irredutível do Outro, com todos o riscos que o encontro exige e toda insegurança e inquietação que ele provoca. $\mathrm{Na}$ educação, o sujeito que não se expõe ao desconhecido é incapaz de sentir a força transformadora do encontro com o Outro, a qual está na base da experiência educativa. Lá onde acontece a educação, produz-se um encontro do professor (não como um sujeito que sabe) com o aluno (não como aquele que não sabe). Uma relação que não pressupõe o exercício de transmissão de saberes, mas "o encontro do que se sabe responsável pelo outro, obrigado a dar-lhe uma resposta na situação de radical alteridade. Estamos, portanto, frente a uma relação ética, não só professoral-técnica entre professor-aluno"(Ortega Ruiz, 2004, p. 4).

Por sua vez, romper com o "pensamento alérgico ao outro" na educação não é algo que acontece de um só golpe, pois requer, entre outras coisas, certo desprendimento de si e exposição ao Outro que nos vem ao encontro na experiência educativa. Pensar a educação para além de uma racionalidade técnica e instrumental que conduz a uma visão objetivadora do Outro exige, de certo modo, realizar aquilo que 
Foucault (2000, p. 128) chama de “conversão do olhar". Essa conversão consiste em transformar o olhar objetivador em um novo olhar sensível ao Outro, um olhar que, antes de ser objetivação do mundo, é exposição e acolhimento ao Outro, conforme indicado por Levinas. Mas como converter a visão objetivadora em olhar sensível ao sofrimento imposto e às injustiças cometidas ao Outro? Que sujeito é capaz de realizar essa conversão? Em vista dessas questões, proponho pensar, com Barcena e Mèlich (2000), a educação como um acontecimento ético no qual a experiência educativa é situada na perspectiva do encontro com a absoluta alteridade do Outro.

Nessa perspectiva, o encontro face a face com o Outro é o elemento que está na base de toda experiência educativa. É o Outro, entendido como significância ética por excelência, que inaugura a relação ética na educação. "O encontro com o outro é o que permite pensar a educação como criação de novidade, como futuro implanificável, como utopia e, finalmente, como nascimento" (idem, p. 154). Nesse contexto, a educação, para além de uma relação epistemológica que envolve sujeito e objeto, é definida por Ortega Ruiz (2004) como um acontecimento ético, ou seja, como uma experiência singular e irrepetível que predominantemente nos dá a oportunidade de experimentar o encontro com o Outro e com isso assistir ao nascimento de algo novo que não sou eu.

Pensar a educação como acontecimento ético implica descrever a experiência educativa como uma maneira de resistência à "horrível novidade" da experiência de totalitarismos e ao massacre e aniquilamento de seres humanos ocorridos no século $\mathrm{XX}$. "Um século que não se caracterizou precisamente pela morte de Deus, senão pela morte do homem, pela morte do humano e da humanidade" (Barcena; Mèlich, 2000, p. 126, grifos do original). Desse modo, consiste em pensar a educação numa perspectiva ética como resistência às formas de naturalização da violência e banalização do humano e criação das condições de possibilidade para a edificação de uma nova e fecunda relação de acolhimento e responsabilidade pelo Outro, por meio do despertar da sensibilidade ética.

Abordar o Outro de frente está na origem de toda relação ética na educação. Pensar a educação como acontecimento ético significa fazer da experiência educativa um lugar de exposição, de desprendimento e de conversão da visão objetivadora sobre o outro, o que supõe assumir uma atitude de abertura, de acolhimento e de escuta sensível à palavra que vem do Outro. Esse duplo movimento - o desprendimento de si e o acolhimento do Outro - está na base da relação ética na educação, pois somente uma educação que se constitui pela relação face a face como exposição, escuta e acolhimento à palavra do Outro é capaz de fazer da experiência educativa um acontecimento ético por excelência.

Convergente com esse modo de pensar a educação, Ortega Ruiz (2004) considera que todo discurso pedagógico está situado em um contexto e responde a ele, sendo alimentado pelas experiências enraizadas na tradição. Isso faz com que o discurso pedagógico seja sempre devedor de uma antropologia e de uma ética. Baseado na inspiração ética levinasiana, Ortega Ruiz (idem) propõe a construção de uma pedagogia da alteridade, na qual a relação mais radical e originária que se 
estabelece entre professor e aluno ou discípulo e mestre na situação educativa é uma relação face a face que se traduz na atitude de acolhida e no compromisso com o educando, quer dizer, uma atitude de responsabilidade e hospitalidade ao dizer do Outro. Isso requer considerar que no seio da experiência educativa não está situada a relação "professoral-técnica" do especialista com o aprendiz, caracterizada pelo ensino e transmissão de conhecimentos, mas a relação ética inaugurada pelo encontro com a alteridade do Outro, relação ética esta que define e constitui como tal a própria ação educativa.

O encontro com o Outro torna possível o processo de estranhamento do mundo familiar e habitual do Mesmo. Contudo, ao mesmo tempo em que a experiência do encontro inicia um processo de estranhamento, ela também provoca uma situação de permanente busca pela familiaridade com o estranho. Perante a irredutível alteridade do Outro, o Mesmo visa permanentemente transformar o estranho e desconhecido em familiar e conhecido, para sair do estado de desconforto provocado pela inquietante epifania do Outro na relação. Anne Dufourmantelle (2003, p. 28) descreve esse processo de familiarização pela seguinte situação:

Quando entramos num lugar desconhecido, a emoção sentida é quase sempre a de uma indefinível inquietude. Depois começa o lento trabalho de familiarização com o desconhecido, e pouco a pouco o mal-estar se interrompe. Uma nova familiaridade se segue ao susto provocado em nós pela irrupção de um outro.

Estranhamento e familiaridade constituem um duplo movimento inaugurado no momento do encontro com o desconhecido. O encontro com o Outro na relação face a face produz uma fratura na consciência, capaz de estremecer a segurança e a certeza do Mesmo, ou seja, a presença do Outro como pura inquietação coloca em questão um mundo até então inquestionável. A irrupção do Outro torna possível o confronto de perspectivas de mundos diferentes, sua interpelação faz vibrar a consciência e desperta o Mesmo do profundo sono egoísta, chamando-o à responsabilidade pelo Outro. A inscrição da responsabilidade, no seio da subjetividade, é algo que acontece para o Outro.

A relação inaugurada no encontro com o Outro, descrita por Levinas como relação face a face, é uma relação de proximidade primordial situada em meio ao processo de familiaridade e estranhamento. Nesse entremeio, a experiência educativa pode ser entendida primeiramente como relação ética, descrita como proximidade, acolhimento e responsabilidade pelo Outro.

Pensar a educação como um acontecimento ético consiste em defini-la como "um evento imprevisível que irrompe de repente e chega sem prévio aviso, que nos põe diante do outro a quem não podemos deixar de olhar e responder" (Ortega Ruiz, 2004, p. 11). Por meio desse encontro inusitado, responder é, antes de tudo, ser inquietado pela presença do Outro que interpela e "sacode eticamente" o Mesmo, invitando-o à responsabilidade. $\mathrm{Na}$ relação face a face, o rosto revela a irredutível alteridade do Outro, sua presença perturba permanentemente o equilíbrio, o gozo e o sono egoísta do Mesmo e produz uma fenda no ser como possibilidade de passagem 
à relação ética de transcendência ao infinito do Outro. A "epifania do rosto" como significância ética permite a ruptura com o estado de indiferença e provoca uma abertura como passagem ao infinitamente Outro. No acontecer dessa relação, a experiência educativa se faz a partir do encontro com a alteridade e inaugura o ensinamento ético da responsabilidade pelo Outro.

Portanto, a subjetividade que se constitui como resposta ética à inquietação do Outro na educação expressa a incondicional responsabilidade pela alteridade. Uma subjetividade insubstituível, capaz de acolher como responsabilidade e responder à palavra do Outro que lhe interpela eticamente. Se, com Nietzsche (1992), aprendemos que a vida só pode ser justificada esteticamente, Levinas nos ensina que apenas eticamente a vida e a educação assumem seu sentido verdadeiramente humano.

\section{REFERÊNCIAS}

Barcena, Fernando; MèLich, Joan-Carles. La educación como acontecimiento ético: natalidad, narración y hospitalidad. Barcelona: Ediciones Paidós, 2000.

Chaui, Marilena. Convite à filosofia. São Paulo: Ática, 2000.

Descartes, René. Meditações sobre a filosofia primeira. Tradução de Fausto Castilho. Campinas: Editora da UNICAMP, 2004.

. Discurso do método. São Paulo: Martins Fontes, 1989.

Dufourmantelle, Anne. Convite. In: __ Anne Dufourmantelle convida Jacques Derrida a falar da hospitalidade. Tradução de Antonio Romane. São Paulo: Escuta, 2003. Foucault, Michel. A arqueologia do saber. Tradução de Luiz Felipe Baeta Neves. Rio de Janeiro: Forense Universitária, 2000.

Ghiraldelli Júnior, Paulo. O que éfilosofia da educação? Rio de Janeiro: DP\&A, 2000. Habermas, Jürgen. O discurso filosófico da modernidade. Tradução de Luiz Sérgio Repa e Rodnei Nascimento. São Paulo: Martins Fontes, 2002.

Hermann, Nadja. Duas perspectivas críticas à soberania do sujeito: Nietzsche e Gadamer. In: Munhoz, Angélica Vier; Feldens, Dinamara; Schuck, Rogério José (Orgs.). Aproximaçôes sobre o sujeito moderno: traçando algumas linhas... Lageado: Ninivates, 2006.

Kant, Immanuel Crítica da razão pura. Tradução de Valério Rohden e Udo Moosburger. São Paulo: Abril Cultural, 1980.v. 2.

Kuiava, Evaldo Antônio. Subjetividade transcendental e alteridade: um estudo sobre a questão do outro em Kant e Levinas. Caxias do Sul: EDUCS, 2003.

Levinas, Emmanuel. Totalidade e infinito. Tradução de José Pinto Ribeiro, Lisboa, Portugal: Edições 70, 2000 [1961].

. De otro modo que ser, o más allá de la esencia. 4. ed. Tradução de Antônio Pintor Ramos. Salamanca: Sígueme, 2003 [1974]. 
. Descobrindo a existência com Husserl e Heidegger. Tradução de Fernanda Oliveira. Lisboa: Instituto Piaget, 1998 [1947].

. Difficile liberté. Essais sur le judaïsme. Paris: Albin Michel, 1963.

. Humanismo do outro homem. Tradução e coordenação de Pergentino S. Pivatto. Petrópolis: Vozes, 1993 [1972].

Nietzsche, Friedrich. O nascimento da tragédia ou helenismo e pessimismo. 2. ed. Tradução de Jaime Guinsburg. São Paulo: Companhia das Letras, 1992.

Ortega Ruiz, Pedro. La educación moral como pedagogía de la alteridad. Revista Española de Pedagogía, año LXII, n. 227, jan./abr. 2004. Disponível em: <http://www. ateiamerica.com/doc/edumoral22.pdf>. Acesso em: 2007.

Pelizzoli, Marcelo Luiz. Levinas: a reconstrução da subjetividade. Porto Alegre: EdiPUCRS, 2002.

SouzA, Ricardo Timm. Razões plurais: itinerários da racionalidade ética no século XX: Adorno, Bérgson, Derrida, Levinas, Rosenzweig. Porto Alegre: EdiPUCRS, 2004.

Susın, Luiz Carlos. Levinas e a reconstrução da subjetividade. Veritas, Porto Alegre: PUCRS, v. 37, n. 147, p. 365-378, set. 1992.

\section{SOBRE O AUTOR}

José Valdinei Albuquerque de Miranda é doutor em educação pela Universidade Federal do Rio Grande do Sul (UFRGS). Professor da Universidade Federal do Pará (UFPA).

E-mail: jneimiranda@ufpa.br

Recebido em agosto de 2011 Aprovado em agosto de 2012 